\title{
Study on the Spatial Distribution of Gansu Longshen Cult in Qing Dynasty Based on ArcGIS
}

\author{
Zhang keze ${ }^{* 1}$ \\ ${ }^{1}$ Collaborative Innovation Center for Security and Development of Western Frontier China, Sichuan University, Chengdu, Sichuan ,610065, \\ China
}

\begin{abstract}
Influenced by the limitations of the times, the agricultural belief and sacrificial system are developed and widely used in the traditional society of China, and the Longshen cult is a typical one. Taking the Gansu Longshen cult in Qing Dynasty as a case, this paper considered that the Longshen temple throughout Gansu are mainly the result of the correspondence between the rain function of Longshen and the characteristics of climate drought. Based on the statistics of the number of Longshen temple, the spatial distribution map of Gansu Longshen cult in Qing Dynasty was drawn by ArcGIS software.
\end{abstract}

\section{Introduction}

In the agriculture-oriented society of ancient China, the Longshen were widely distributed as part of the agricultural sacrificial system. The folk society of Gansu in the Qing Dynasty generally worshiped the Longshen, which was closely related to the role of the Longshen in the traditional Chinese folk beliefs and the natural environment of Gansu. On the one hand, the Longshen temple throughout Gansu were due to the correspondence between the rainfall function of the Longshen and the characteristics of climate drought. On the other hand, there were differences due to different agricultural forms.

\section{The background of Gansu Longshen Cult in Qing Dynasty}

\subsection{Rainfall: the main function of Longshen}

Water resources play an important role in the development of agriculture. In a society of "building a country by agriculture", water resources are the source of the survival and development of agriculture, farmers and even state power. Ancient ancestors generally believed that precipitation was mainly dominated by gods. On the basis of this understanding, the relationship between precipitation and Longshen was linked for a long time, and a set of quite complete rain seeking ceremony was gradually developed. With the popularity of the Buddhist concept of Longwang, the cult of Longshen has been widely spread in civil society, and gradually from the folk to the temple, completed the institutionalized leap. As the god in charge of Rain Water's apologies in the ancient Chinese agricultural belief system, Rainfall is its most basic function, and it is also the fundamental reason why it can be widely worshipped in an agricultural society. It is nothing more than a kind of expectation for the rain to be worshipped by the people.

In the ancient Chinese ancestors' perception, the dragon, as a deity specializing in rainfall, was the main object chosen by civil society when seeking rain in every drought. The association between dragon and rain was established as early as the pre-Qin period. Although the association between dragon and rain was established very early, it was only during the Han Dynasty that a set of strict rituals for seeking rain took shape. For example, Dong Zhongshu made a detailed account of the ritual of seeking rain in the four seasons of spring, summer, autumn and winter when there was a drought. With the improvement of rain rituals in civil society and the widespread spread of the concept of the Longwang in Buddhism, the institutionalization of the Longshen was further promoted, and gradually evolved from a spontaneous act in civil society to a formal system at the national level. Since the Tang Dynasty, the belief in Longshen has gradually entered the formal system of the state and become an important part of the state ritual system. Through the continuous recognition and strengthening of the official system since the Tang and Song dynasties, the Longshen were gradually promoted and developed and gradually extended to the whole country.

\subsection{Drought: climatic characteristics of Gansu Province}

Gansu is deeply inland in northwest China, and its topography and geomorphology are complex. It is the rendezvous area of Qinghai-Xizang Plateau, Loess Plateau and Mongolian Plateau. Most of the areas in Gansu are arid areas with dry climate and less rain, the annual precipitation is $42 \leq 760 \mathrm{~mm}^{[1]}$, and the spatial distribution of precipitation is also very uneven, showing the law of

"Corresponding author's e-mail: 357243039@qq.com 
decreasing from southeast to northwest on the whole. The annual precipitation in the southeast of Longnan is $600 \leq$ $900 \mathrm{~mm}$, and the climate is relatively humid. The annual precipitation in southeastern Qinghai, Hedong of Gansu and southern Ningxia is $300 \leq 600 \mathrm{~mm}$, mostly semi-arid and semi-humid climate, while the annual precipitation in Hexi Corridor area and northern Ningxia is $15 \leq 300 \mathrm{~mm}$, which is arid and extremely arid climate area ${ }^{[2]}$, and drought and less rain is the background of Gansu climate. This also determines that drought has become a key factor perplexing the development of agriculture in Gansu Province. In the traditional society where the level of productive forces is backward, the nearly extinct caused by drought has occurred from time to time. The number of droughts occurred in the history of Gansu is very frequent. If the number of droughts occurred between the Western Han Dynasty and the Republic of China, the average number of droughts occurred about once in three years. If the number of droughts from the Sui Dynasty to the Republic of China is counted, the average drought occurs once in two years. It can be said that the overall characteristics of Gansu climate can be vividly explained by two droughts in three years ${ }^{[3]}$. At the same time, affected by geographical location and other regional factors, the drought suffered by different areas in Gansu will be different. In terms of the administrative scope of Gansu in the Qing dynasty, according to the different topography, climate and other areas under its jurisdiction can be divided into Longdong (Qingyang, Pingliang, Jingzhou, Guyuan and Huapingchuan), Longnan (Qinzhou and Jiezhou), Longzhong (Lanzhou and Gongchang), Hexi (Liangzhou, Ganzhou, Suzhou and Anxi), Haidong (Xining), Ningbei (Ningxia) different geographical units. According to the relevant statistics in the Qing dynasty archives, 290 droughts occurred in the Longdong region; 77 droughts occurred in the Longnan region; 408 droughts occurred in the Longzhong region; 154 droughts occurred in the Hexi region; 47 droughts occurred in the Haidong region; 107 droughts occurred in the Ningbei region ${ }^{[4]}$.

In traditional societies with low productivity levels, the effective means to face frequent droughts were extremely limited, and the power of the gods to counteract them became one of the options. The high degree of correlation between the Longshen role in traditional Chinese agricultural rituals and Gansu's climate, which is characterized by dryness and low rainfall, created an innate condition for the widespread distribution of Longshen cult in Gansu, satisfying the spiritual need of the people to pray for a good harvest in a drought-stricken agricultural society, which explains the socio-cultural phenomenon of Longshen temple all over Gansu during the Qing Dynasty.

\section{The Spatial Distribution of Gansu Longshen Cult in Qing Dynasty}

As an encyclopedia documenting the political, economic and social conditions of a place, local chronicles have rich historical data value and are an important entrance to the study of regional social history ${ }^{[5]}$. In order to master the actual distribution of Gansu Longshen cult in Qing Dynasty as much as possible, this paper starts with Gansu Tongzhi during Qianlong period and Gansu xin Tongzhi during Guang Xu's years, supplemented by the local chronicles of Gansu counties, using the relevant contents of the chronicles, on the basis of mutual reference and supplement, outlines the complete schema of Gansu local social Longshen cult in Qing Dynasty. It should be explained that due to the regional differences, in the local historical records of Gansu Province, in addition to the Longwang, there are Qiushen, Quanshen, Chaonaqiu and so on, and even some personification of the Longshen. Because it has the function of praying for rain in a general sense, it is also regarded as the Longshen cult in a wide sense and included in the statistical scope in the process of investigating its distribution. In addition, the administrative division of Gansu in Qing Dynasty is slightly different from that at present, which roughly includes some regions in Ningxia and Qinghai today. In order to fully reflect the distribution of Gansu Longshen cult in Qing Dynasty, some areas belonging to the above provinces and autonomous regions will still be included in the statistical scope.

With the help of the relevant records in the local historical records, it can be roughly outlined that the Gansu Longshen cult in Qing Dynasty is a common cultural phenomenon. Temples worshiped to the Longshen are widely distributed in Jiezhou, where the climate is relatively humid, and in Anxi, where the climate is relatively dry. The distribution characteristics of Longshen cult in Gansu Province are not only wide in scope, but also different among regions (see Figure 1). The narrow geographical characteristics of Gansu Province have created great differences in the natural environment between the eastern and western regions, on the basis of which different agricultural areas have been formed. Generally speaking, the Yellow River has been used as the boundary to form Hedong area (Lanzhou, Gongchang, Pingliang, Qingyang, Jiezhou, Qinzhou, Jingzhou, Guyuan, Huapingchuan) and Hexi (Liangzhou, Ganzhou, Ningxia, Xining, Anxi, Suzhou). Hedong is a rain-fed agricultural area, Hexi is an irrigated agricultural area. The emergence of Longshen cult is mainly related to agriculture ${ }^{[6]}$, so when investigating the distribution difference between Longshen cult regions, we can choose different agricultural areas to observe. From the statistical results of the belief distribution of Gansu Longshen cult in Qing Dynasty, it can be seen that the number of Longshen temples in the rain-fed agricultural area in the east of the river is slightly lower than that in the irrigated agricultural area in Hexi. 


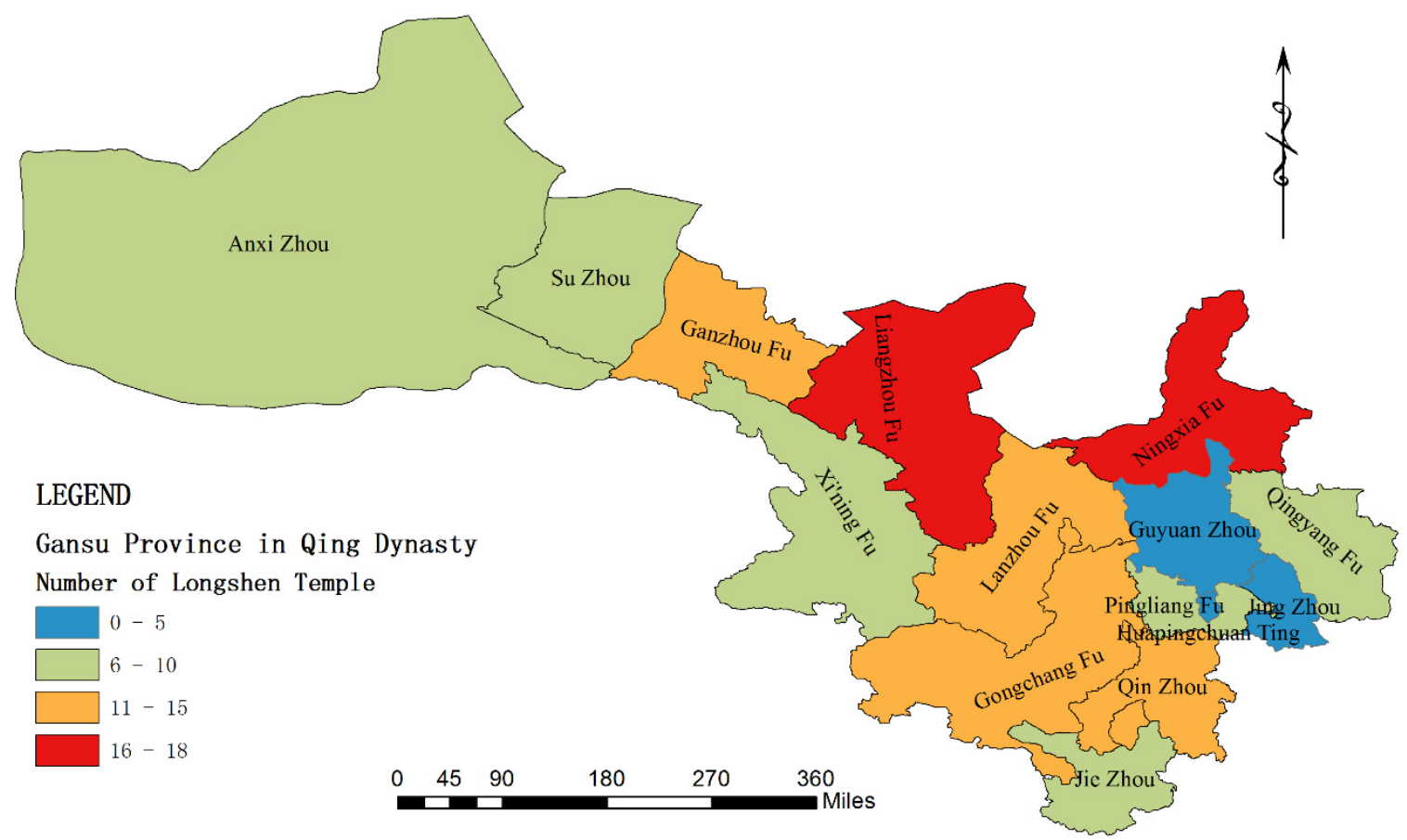

Figure 1. Spatial distribution map of Gansu Longshen temple in Qing Dynasty

\section{Conclusions}

After investigating the distribution of Gansu Longshen cult in Qing Dynasty, it is found that the widely distributed Longshen temple in arid and rainy Gansu reflects a general psychological state of people 's desire for harvest in the traditional agricultural society with low productivity. As a symbolic symbol of carrying agricultural civilization, Longshen cult not only expresses a hope for rich life, but also is affected by climate and agricultural form in the process of its historical transmission and evolution. In fact, it is a cultural phenomenon shaped by multiple factors. Therefore, when examining the Longshen Cult during the traditional period, especially under the perspective of modern science, we cannot simply attribute the Longshen Cult as a product of ignorance under the backward productivity, but as a long-standing social and cultural phenomenon, engraved with a deep brand of the times and rich in economic, political and social cultural connotations.

\section{References}

1. Chen Peixuan,Lu Guoyang,Bai Huzhi.(2020) Analysis of the Main Characteristics and Change Trend of Arid Climate-Taking Gansu Province as an Example. Anhui agricultural sciences ,18:210-219.

2. Zhang Qiang, Wang Runyuan and Deng Zhenyong. (2012) Effects of arid climate change on agriculture and ecology in northwest China. Meteorological Press, Beijing.

3. Yuan Lin. (1994) A Study on the Law of Drought Occurrence in the Historical Gansu,Ningxia and Qinghai. Journal of Lanzhou University, 02: 111-116.

4. Tan Xuming. (2013) Qing dynasty drought archives historical materials. China Book Publishing House, Beijing.
5. Chang Jianhua. (2006) Value of Chinese Local Chronicles as Social History Data. Chinese Social and Historical Review, 00: 61-73.

6. Zhao Shiyu. (2002) Revelry and Ordinary LifeThe Temple Fair and the Folk Society Since Ming and Qing Dynasties. SDX Joint Publishing Company, Beijing. 